younger (under 19) or older (over 35) mothers (and hence at increased obstetric risk), have more unplanned pregnancies and are more likely to have had a termination of pregnancy. Women with schizophrenia are more socially disadvantaged than women in the general population, more likely to use illicit drugs before pregnancy, and to drink alcohol and/ or continue to use drugs during pregnancy, which confers additional risks to the fetus.

Even when smoking and other risk factors such as maternal age, education and pregnancy-induced hypertension are controlled for, the odds of poor outcomes such as low birth weight (LBW), small for gestational age (SGA) infants, preterm delivery and stillbirth are higher in women with schizophrenia. Complications also occur more frequently, such as placental abruption, antepartum haemorrhage, the toxic side-effects of alcohol and illicit drugs and infants with cardiovascular congenital anomalies (most commonly patent ductus arteriosus).

Obesity is increasing in high-income countries and being overweight and folate deficient when pregnant increases the risk of neural tube defects. Women with schizophrenia may become obese through poor diet or the weight gain associated with atypical antipsychotics; it is not known, however, whether the risk of neural tube defects may be further heightened as a direct metabolic consequence of schizophrenia. Patients with schizophrenia are also at increased risk of impaired glucose tolerance and diabetes, particularly if they are taking certain atypical antipsychotics. When pregnant, this renders them at higher risk of gestational diabetes, which confers greater morbidity for both mother and fetus. Obesity in pregnancy also increases obstetric risk and is associated with being less likely to have a spontaneous onset of labour, more blood loss in labour, heavier babies and longer hospital stays. Many of the examinations and investigations which are part of antenatal care are more difficult in an obese woman. For example, it is harder to palpate the uterus and ultrasound penetrates fat very poorly.

Women with tightly defined schizophrenia who remain on medication are less likely to relapse after delivery than women with mood disorders. However, a fifth of those who have had admissions before they became pregnant will relapse after delivery, this relapse being more likely if medication is discontinued.

\section{Self-harm and suicide}

Self-harm in pregnancy is most often an overdose of the most accessible medication: over-the-counter analgesics, iron or vitamins. Issues related to pregnancy and interpersonal difficulties are the most frequently cited reasons for the overdose. Suicidal ideation is more likely to occur in women with a history of physical or sexual abuse.

Self-poisoning during pregnancy increases the risk of preterm labour, the need for Caesarean section and blood transfusion, and increases the likelihood of respiratory distress syndrome and neonatal death. One of the best predictors of self-harm in pregnancy is substance misuse.

Women with psychosis or severe depressive illnesses during pregnancy and the postpartum period who are suicidal tend to use violent methods, most frequently hanging or jumping from a height, drowning, self-immolation or guns in the USA and are hence more likely to succeed in killing themselves. Maternal suicide has become the most common cause of maternal death in the UK in recent years.

\section{Conclusions}

Pregnancy and the postpartum period can be a difficult and very risky time for many women with mental disorders. A woman's mental state, associated behaviours or treatment may confer significant risk to her fetus or infant. It is therefore crucial that mental health professionals working with women during their reproductive years are aware of these risks and engage in proactive management with sexual health, family planning and maternity services.

\section{References}

Astrachan-Fletcher., E., Veldhuis, C., Lively, N., et al (2008) The reciprocal effects of eating disorders and the postpartum period: a review of the literature and recommendations for clinical care. Journal of Women's Health, 17, 227-239.

Bloch, M., Rotenberg, N., Koren, D., et al (2005) Risk factors associated with the development of postpartum mood disorders. Journal of Affective Disorders, 88, 9-18.

Halbreich, U. \& Karkun, S. (2006) Cross-cultural and social diversity of prevalence of postpartum depression and depressive symptoms. Journal of Affective Disorders, 91, 97-111.

Kim, H. G., Mandell, M., Crandall, C., et al (2006) Antenatal psychiatric illness and adequacy of prenatal care in an ethnically diverse innercity obstetric population. Archives of Women's Mental Health, 9, 103-107.

Stewart, R. C. (2007) Maternal depression and infant growth: a review of recent evidence. Maternal and Child Nutrition, 3, 94-107.

Viguera, A. C., Whitfield, T., Baldessarini, R. J., et al (2007) Risk of recurrence in women with bipolar disorder during pregnancy: prospective study of mood stabilizer discontinuation. American Journal of Psychiatry, 164, 1817-1824.

\section{Meeting of the Psychiatric Associations of Europe, London}

On 27 April 2010 the College hosted a meeting of psychiatric associations from across Europe with the view to exploring common issues and concerns relating to mental health, developing common strands of work and responding collaboratively to issues affecting psychiatry and psychiatric services across Europe.

The meeting brought together high-ranking representatives of psychiatric associations in Belgium, the Netherlands, Croatia, Czech Republic, Finland, Germany, Ireland, Italy, Norway, Russia, Slovakia and Spain, as well as the World Health Organization (WHO) and the European Parliament. 
Discussions focused around professional standards, quality and content of training and service development, and highlighted common interests and goals faced by professional organisations in Europe as well as the differences shaped by national economic, political and social contexts. Dr Muijen led on the relationship between the WHO and various organisations. The participants recognised the need for a Europe-wide effective body with clear terms of reference and sufficient resources to advocate for mental health. The group felt that liaison with key stakeholders in Europe needs to be improved. It was agreed that an informal forum initially would be very helpful and the right way forward. A cautious and measured approach to further collaborative work was accepted and discussions will continue at forthcoming meetings in Berlin (2010) and Amsterdam (2011).

\section{College visit to Bangalore, India}

In March 2010 the College officers were invited by the National Institute of Mental Health and Neurosciences (NIMHANS) in Bangalore to a 2-day conference where, in a prelude to International Women's Day, the President gave an illustrated talk entitled 'The mind of a woman: portrayal in Bollywood', which emphasised the importance of accurate and responsible portrayal of mental illness in film.
Professor Anthony Bateman, Chief Examiner, used the occasion to explore the feasibility of running the MRCPsych examination in India. Professor Bateman and Dr Amit Malik, among others, talked about the changes to postgraduate training in the UK, such as competence-based training and workplace assessments.

The conference was crowned with the signing of a memorandum of understanding between the College and NIMHANS to set out a general framework for collaboration and exchange of research, experience and the organisation of joint activities.

\section{The College launches a new book review section online}

If you enjoy reading, or perhaps recommend books to your patients, then please consider contributing to our new book review section of the College website (http://www.rcpsych. ac.uk/mentalhealthinfo/bookreviews.aspx). You can read reviews, sort books according to the reviewers' ratings or click on a link to buy a book from Amazon. If you do not have time to write a review perhaps some of your patients might like to contribute. We are interested in any type of book, including fiction, self-help or academic books, as long as they have a mental health theme.

\section{Clinical Assessment of Skills and Competencies examination}

Sir:

As a psychiatric trainee I had the opportunity to appear for the Clinical Assessment of Skills and Competencies (CASC) examination as an exit exam towards MRCPsych. In a letter published in the April 2010 issue of International Psychiatry (volume 7, number 2, p. 51) authors Joan M. Anzia and David J. Lynn say that they were impressed by the efficiency and economy of the design and implementation. The purpose of the present letter is to raise some of the concerns candidates have.

In the examination we never know what is expected of us to pass a certain station, as it is a double-blind procedure where we do not know what is in the patient's script and neither do we know what weight is attached to each task in the examiner's script in each scenario. The College claims that simulations are true to life, which is right, but we do not see patients for 7-10 minutes.

In the letter it is stated that consistent, clear internal validity is attained, but reliability is ignored. There are two pass grades: ' $A$ ', which means a candidate displayed 'clear competencies'; and 'B', which reflects 'adequate' competencies. As a trainee I claim that this is the area where the subjectivity of individual examiners plays a huge role. It is entirely up to the individual examiner to differentiate between clear, adequate and unsystematic approaches. Over the past 2 years, pass rates have been around only $30 \%$, which in itself raises questions about the appropriateness of the CASC examination. There is a sense of mistrust, as the College does not mention on its website the relevance of seeing patients in 7-10 minutes or how the pass mark of 12 out of 16 stations was derived.

There is no record of the candidate's performance at CASC, so really we cannot challenge a result if we are not satisfied. If we fail, we get utterly unhelpful feedback. For example, such feedback might say either that there was concern or that there was no concern. Skills like 'fluency' or 'analysis and synthesis of opinion' or, say, 'lack of focus on the task' are not quantifiable. How would I know what it was in my performance that made the examiner think that my analysis and synthesis of opinion were weak?

Lastly, it was stated in the letter that the CASC examination is economic, but this is not true. Over the past few years the examination fee has been raised consistently, to the point where it now costs as much as a third of our monthly salary, excluding accommodation and travel expenses.

I would say that the reliability of this examination is questionable and in statistical terms the percentage pass reflects chance only.

Shailesh Kesharwani Core Psychiatric Trainee, South West Peninsula Psychiatric Rotational Training Scheme, Plymouth, UK, email shailesh.kesharwani@plymouth.nhs.uk 